\title{
Préstamos con interés encubierto de cristianos y judíos en la Galicia del siglo $\mathrm{XV}^{*}$
}

\author{
María Gloria de Antonio Rubio ** \\ Instituto de Estudios Gallegos «Padre Sarmiento»-CSIC
}

Todos los contratos de préstamo, salvo los realizados entre personas con una relación de carácter familiar o de amistad, son de carácter mercantil, es decir, persiguen un beneficio para el prestamista. Sin embargo, las limitaciones legales y religiosas sobre el cobro de intereses obligaron a judíos y cristianos a desarrollar fórmulas para ocultarlos: en unos casos, falseando la cantidad que había sido prestada; en otros, exigiendo la devolución de la cantidad prestada con un bien o el valor de ese bien en el mercado pero nunca el dinero inicial. El marco documental, geográfico y cronológico elegido para analizar este tipo de préstamos son dos libros de notarios gallegos del siglo XV, restricción que no impide que los métodos propuestos sean aplicables a otros ámbitos.

Palabras Clave: Edad Media; Historia económica; usura; minorías.

Loans with Hidden Interest Made by Christians and Jews in Galicia throughout THE 15 ${ }^{\text {тн }}$ CENTURY.- All the loan agreements are commercial, except the ones made among friends or family relatives. That is, they look for some benefits for the loaner. However, the legal and religious restrictions on charging interest forced Jews and Christians to develop some techniques for hiding them. In some cases, they falsified the amount of money that had been lent. In other cases, they demanded the repayment of the amount of money that had been loaned in exchange for some property or its value in the market but not for money. The documentary, geographical and chronological frame that has been chosen to analyse this type of loans comes from two notarial books of the 15th century. However, this restriction does not prevent the proposed methods from being applicable to other fields.

KeYwords: Middle Ages; Economic History; Usury; Minorities.

"Este artículo ha sido desarrollado dentro del proyecto Linaje, parentela y poder: la pirámide nobiliaria gallega (siglos XIII al XV) (II), dirigido por el Dr. Eduardo Pardo de Guevara y financiado por el Ministerio de Economía y Competitividad [ref. núm. HAR2013-42985-P].

**mgloria.deantonio@csic.es

Copyright: (C) 2016 CSIC. Este es un artículo de acceso abierto distribuido bajo los términos de una licencia de uso y distribución Creative Commons Attribution (CC-by) España 3.0. 


\section{INTRODUCCIÓN}

El contrato de préstamo ha sido estudiado desde muchas y variadas ópticas: legales, jurídicas, económicas, teológicas, etc. No obstante, en esta ocasión, lo que se pretende es, por un lado, mostrar una técnica, aparentemente legal, utilizada para ocultar el interés en un préstamo y, por otro, enunciar una fórmula que permita calcular el porcentaje realmente aplicado. Todo ello circunscrito a un espacio concreto, Galicia; a un período de tiempo determinado, el siglo XV; y a dos libros de notarios que, aunque ya han sido publicados como fuentes primarias, no están acompañados de ningún tipo de estudio o análisis de contenido: el Libro de notas de Alvaro Afonso. Ourense, $1434^{1}$ y el Minutario notarial de Pontevedra (1433-1435) $)^{2}$. Esta limitación geográfica, temporal y documental no impide, sin embargo, que la técnica y fórmula propuestas sean aplicables a otros ámbitos espaciales, temporales o documentales.

Metodológicamente, se analizará, en primer lugar, la técnica de incluir los intereses en la cantidad prestada. Para clarificar como fue técnicamente posible el ocultamiento de los intereses realmente aplicados se recurrirá a conceptos derivados del Derecho, tales como la naturaleza mercantil del préstamo y las diferencias entre el contrato real del préstamo y la obligación de pago presentada ante el notario, para posteriormente, analizar las coincidencias y divergencias en el modelo utilizado por judíos y por cristianos. En segundo lugar, y tomando como base un modelo de contrato en el que el prestamista solamente permite la devolución de la cantidad prestada con un bien o su valor en el mercado, se calculará el porcentaje realmente aplicado, aunque por las particularidades de la documentación nunca se obtendrán cantidades exactas. Para ello, se fijará el precio mínimo aproximado de la unidad de medida del bien, en este caso concreto el del moyo ${ }^{3}$ de

${ }^{1}$ A. López Carreira (ed.), Libro de notas de Alvaro Afonso. Ourense, 1434 (Santiago de Compostela 2000). Los documentos que se utilizarán en este artículo serán copiados exactamente igual que el autor los ha publicado sin intercalar anotaciones o correcciones personales.

2 Á. Rodríguez González y J. Armas Castro (eds.), Minutario notarial de Pontevedra (1433-1435) (Santiago de Compostela 1992). Los documentos que se utilizarán en este artículo serán copiados exactamente igual que los autores los han publicado sin intercalar anotaciones o correcciones personales.

${ }^{3}$ El diferente valor de las medidas de capacidad hace que se haya considerado el valor 
vino en Ourense. Una vez obtenido este dato y aplicando la fórmula general del interés simple se logrará una aproximación al porcentaje de interés realmente cobrado tanto por judíos como por cristianos.

\section{Métodos de ocultación de intereses en la Galicia del siglo XV}

Dado que, al menos desde mediados del siglo XIII, a los cristianos les está expresamente prohibido prestar a interés y, en rigor, tampoco los judíos podían hacerlo con miembros de su propia comunidad como establecía el Antiguo Testamento, se desarrollaron diversas ficciones legales que los miembros de ambas comunidades religiosas utilizaron para evadir tales restricciones ${ }^{4}$. La Galicia del siglo XV no fue ajena a esta situación general y en ella se utilizaron, al menos, dos técnicas para ocultar los intereses realmente cobrados: 1) incluir los intereses en la cantidad prestada y 2) permitir la devolución de la cantidad prestada exclusivamente con un bien o su valor en el mercado.

\subsection{Incluir los intereses en la cantidad prestada}

Con la técnica de incluir los intereses en la cantidad prestada, el deudor se comprometía a devolver la misma cantidad que le había sido entregada con lo que, teóricamente, se trataba de un préstamo gratuito en el que el prestamista no obtenía ninguna ganancia. Sin embargo, no obtener un beneficio en razón del riesgo que se asume al entregar un bien -habitualmente dinero- es contradictorio con la propia naturaleza mercantil del préstamo, cuyo fin es, precisamente, obtener unos rendimientos por el bien o dinero adelantado. En consecuencia, ocultar el verdadero interés fue imprescindible para el prestamista. El encubrimiento fue técnicamente posible porque el contrato real del préstamo -en el que obligatoriamente tendrían que constar, entre otros conceptos, la cantidad prestada y el interés aplicado- se realizaba con anterioridad y ante el notario se registraba exclusivamente la obligación de pago, es decir, el compromiso del prestatario de devolver la misma cuantía que había recibido del prestamista. El notario en su libro de notas apuntaba y daba fe de lo que ante él las partes reconocían haber

del moyo como equivalente a 128 litros; cf. Dicionario de Galego (Vigo 2004) s.p.v.

${ }^{4}$ O. Colombo, «La negociación en torno a la usura en Castilla, 1258-1405. Economía, Poder y Religión en la Baja Edad Media», Anales de la Universidad de Alicante, Historia Medieval 14 (2003-2006) págs. 85-110: 89-90. 
prestado y/o recibido pero no de la entrega efectiva del dinero realizada con anterioridad y no en su presencia. Sirva como ejemplo la nota de Álvaro Afonso, datada el 18 de octubre de 1434, donde se recoge que Martín Anes

reçebeu enprestados de Nuno Peres mercador vesiño da vyla de Ponte Vedra, seysçentos et noveenta mrs. branca en tres dños., de que se deu por pago, et os quaes ditos seysçentos e noveenta mrs. se obrigou delos pagar ata día de domingo de pascoella primeira que ven. Penna des mrs. ${ }^{5}$

En este caso el notario sólo puede dar fe de lo que Martín Anes dice haber recibido, seiscientos noventa maravedíes (en adelante mrs.), ignorando si en esa cantidad estaban incluidos intereses o no. Muy diferente es el contrato realizado también en Ourense por el mismo notario, Álvaro Afonso, el 4 de agosto de 1434, por el que Fernando García

reçebeu enprestados de Gonçalvo Yanes mercador vesiño dOurense, mill et dosentos mrs. branca en tres dños., os quaes IMCC.- reçebeu en dños. feitos et contados en presença de min o notario e tests. de juso escriptas, e obrigouse de lle dar os ditos mill e dosentos ... Penna des mrs. ${ }^{6}$

En este caso, el acreedor, Fernando García, sí recibió realmente los 1.200 mrs., los cuales fueron contados en presencia del notario y de testigos, lo que permite afirmar que en la cantidad prestada no estaba incluido ningún tipo de interés. Por lo tanto, aunque el prestatario se comprometiera a devolver la misma cantidad que había recibido, la presencia o no del notario en el momento de la entrega del dinero, será uno de los factores determinantes para diferenciar si en la cantidad prestada estaban o no incluidos intereses.

Otro factor que puede ayudar a identificar este tipo de ocultamiento es la, anteriormente mencionada, naturaleza mercantil del préstamo. Es decir, cuando el prestamista persigue un beneficio, en razón del riesgo que asume al entregar un bien o cierta cantidad de dinero, trata de asegurarlo incluyendo cláusulas de penalización para el caso de incumplimiento. En este sentido son habituales expresiones tales como: «so pena de tres solidos cada dia, quantos dias pasaren delo plazo endeante», «so pena do doblo», o simplemente, «penna dous mrs.». Expresiones que aparecen

\footnotetext{
${ }^{5}$ López CARReIra, Libro de notas, pág. 226, doc. 448.

${ }^{6}$ López CARreira, Libro de notas, pág. 176, doc. 336.
} 
siempre excepto cuando la naturaleza del préstamo no es mercantil, por ejemplo el realizado entre familiares ${ }^{7}$.

En consecuencia, es lícito afirmar que, en las obligaciones de pago en las que el prestatario se compromete a devolver la misma cantidad que le había sido prestada pero cuya entrega no se ha realizado en presencia del notario, y en la que, además, figuren cláusulas de penalización, el prestamista ocultaba su ganancia incluyéndola en la cantidad total a devolver.

Esta técnica fue utilizada en Galicia tanto en préstamos entre cristianos como entre judíos y cristianos. Un ejemplo del primer caso es la nota registrada el 19 de abril de 1433 en el Minutario Notarial de Pontevedra (14331435), por la que Juan do Rego se obligaba a pagar a Gonçalvo Fernandes de Barragãas los doscientos ochenta y dos mrs. que le había prestado:

Sabean todos que eu Juan do Rego, morador ẽna fiigresia de Santa Maria d'Alba, que soo presente, confeso et outorgo que devo et ey de dar et pagar a vos Gonçalvo Fernandes de Barragãas, que sodes presente, dosentos et oytenta et dous mrs. da moeda vella, contando a branqua en tres dineiros, os quaes ditos CCLXXXII mrs. da dita moeda me vos enprestates por nos faser amor et graça et os eu ja en meu jur et poder et renunçio etc... et se o dizer etc.. Et os quaes ditos dosentos et oytenta et dous mrs. da dita moeda vos prometo et outorgo de dar doje este dia ata dia de San Martiño do mes de novenbro primeiro que ven por min et por todos meus bẽes et so pena do doblo et ante me obligo etc .. et a pena etc.. Et eu o dito Gonçalves Fernandes, que soo presente asi o resçebo ${ }^{8}$.

Un ejemplo del segundo se registró en Ourense, el 14 de junio de 1455, cuando Fernando González obligó sus bienes para garantizar el préstamo que Pedro de Reza había recibido del sastre, alfayate, Mosé de León:

En este dito dia enna dita çibdade, fernando gonçalves da corredoyra, vesinno da dita çibdade, se obrigou con todos seus beens de dar e pagar a mose de leon, alfayate, vesinno dita çibdade, en nome e en vos de pero de reça, çento e triinta mrs. vellos que o dito mose enprestara ao dito pero de reça, os quaes ditos C XXX mrs. prometeo de lle dar e pagar o dito fernando gonçalves en esta çibdade fasta en fin do mes de jullio primeiro que

\footnotetext{
${ }^{7}$ Rodríguez González y Armas Castro, Minutario notarial, pág. 135, doc. 99.

${ }^{8}$ Rodríguez González y Armas Castro, Minutario notarial, pág. 29, doc. 11.
} 
ben, su pena do dobro da dita contia; deu poder aos juises desta çibdade e a outras justiças e renunçiou etç. carta firme etç. ${ }^{9}$

Ante el mismo hecho jurídico, la obligación de pago, ambos modelos presentan divergencias y similitudes. Divergencias en cuanto al uso de las expresiones «por nos faser amor et graça»y «renuncio». Similitudes en lo que se refiere a los comparecientes, las cantidades prestadas o las fechas de vencimiento.

\subsubsection{Divergencias}

La expresión «por nos faser amor et graça», escrita con muy diversas grafías, es el reflejo en la documentación gallega de la naturaleza jurídica del contrato de préstamo recogida en el Código de Las Siete Partidas, en la que se especifica que todo préstamo debe ser «un pleyto de gracia», por lo que resulta esencial su carácter gratuito ${ }^{10}$. Expresión que no aparece cuando el prestamista es judío ${ }^{11}$, y que sí lo hace-aunque no en todas las ocasiones- cuando el prestamista es cristiano ${ }^{12}$.

El término «renuncio»se refiere a una excepción procesal por la que, cuando un acreedor interponía una demanda por impago de una deuda durante los dos primeros años tras celebrarse el contrato, alegando el deudor la citada excepción se trasladaba al acreedor la carga de probar esta entrega para continuar el proceso ya iniciado. Es decir, el prestamista tenía que probar la cantidad entregada y cualquier forma de interés que hubiera aplicado quedaría al descubierto. Ahora bien, en el caso de que el deudor

${ }^{9}$ A. López CARreira, «Contribución ó estudo da Xudería ourensá Baixomedieval», en Xudeos e Conversos na Historia, ed. C. BARros. Vol. II (Santiago de Compostela 1994) págs. 201-217: 214, doc. 30.

${ }^{10}$ J. M. Uruburu Colsa, La vida jurídica en Madrid a fines de la Edad Media (Madrid 2006) pág. 73.

${ }^{11}$ López CARreira, Libro de notas, págs. 15, 75-76, 136, 163, 166, 171-172, 173-174, 210 y 268 , docs. $6,128,244,303,311,325,330,413$ y 532.

${ }^{12}$ Rodríguez González y Armas Castro, Minutario notarial, págs. 29, 32, 37, 39, 40, 48-49, 73-74, 105-106, 131 у 161, docs. 11, 16, 21, 24, 25, 32, 52, 73, 96 у 119. Alguna o ninguna de estas dos expresiones en las págs. 37-38, 45, 156 y 162, docs. 22 , 29,113 y 121. Sin embargo en LóPEZ CARREIRA, Libro de notas, no se registra nunca la expresión «por nos faser amor et graça», en ninguna de sus variantes, mientras que el término «renuncio» lo hace en dos ocasiones, págs. 83 y 84-85, docs. 146 y 150. 
renunciase en la misma carta de préstamo a ampararse en dicha excepción, no podría alegarla posteriormente ${ }^{13}$. En este caso, le correspondería al deudor la prueba, pero como, ante notario, el prestatario se había comprometido a pagar la misma cantidad que había recibido del prestamista, éste quedaba protegido aunque hubiera aplicado algún tipo de interés. La renuncia a esta excepción provocó un efecto inmediato, como es el de otorgar mayor seguridad jurídica al contrato celebrado.

\subsubsection{Similitudes}

Por lo que respecta a las similitudes, en ambos modelos se registran como comparecientes la figura del notario -que da fe pública de lo que ante él sucede-, el/los fiadores -persona o personas que prestaban una garantía personal, por medio de la cual se obligaban conjuntamente con el principal deudor de un contrato-, los testigos -otorgantes de fe privada sobre los hechos que ante ellos ocurren- y, lógicamente, el prestamista y el prestatario. Sobre estos dos últimos, la legislación territorial castellana bajomedieval muestra unos criterios muy amplios y flexibles en lo que respecta a la capacidad jurídica y de obrar requeridas para celebrar un contrato de préstamo. Esta amplitud de criterio posibilitó que personas de muy distinta condición y oficio otorgaran y/o recibieran préstamos ${ }^{14}$. En Galicia, concretamente entre los cristianos, lo hicieron artesanos y profesionales ${ }^{15}$, escuderos ${ }^{16}$, cléri$\operatorname{gos}^{17}$ y mujeres que al quedarse viudas solían continuar con los negocios de sus maridos ${ }^{18}$ o que actuaron en solitario sin especificar su estado civil ${ }^{19}$. En-

${ }^{13}$ Uruburu Colsa, La vida jurídica en Madrid, pág. 90.

${ }^{14}$ Uruburu Colsa, La vida jurídica en Madrid, pág. 79.

${ }^{15}$ Rodríguez González y Armas Castro, Minutario notarial: un barbero (pág. 39, doc. 24), un carnicero (págs. 37-38, doc. 22), un carpintero (págs. 73-74, doc. 52), un criado (págs. 105-106, doc. 73), un mercader (págs. 40, 156, docs. 25, 113), un notario (pág. 161, doc. 119) y un sastre (pág. 45, doc. 29).

${ }^{16}$ Rodríguez González y Armas Castro, Minutario notarial, pág. 131, doc. 96.

${ }^{17}$ Rodríguez González y Armas Castro, Minutario notarial, pág. 32, doc. 16, como prestamista, y pág. 131, doc. 96, como prestatario.

${ }^{18}$ E. Cantera Montenegro, «La mujer judía en la España Medieval», Espacio, Tiempo y Forma. Serie III, $H^{a}$ Medieval 2 (1989) págs. 37-64: 59-60; RodríGuEZ GonZÁLEZ y Armas Castro, Minutario notarial de Pontevedra, págs. 48-49, doc. 32.

${ }^{19}$ Rodríguez González y Armas CAstro, Minutario notarial, pág. 37, doc. 21. 
tre los judíos ejercieron el préstamo recaudadores como Abrahán de León y Judá Pérez ${ }^{20}$, varios plateros en Ourense y Tui ${ }^{21}$ y, aunque sólo una vez, un sastre $^{22}$. Todos los documentos de préstamo analizados, tanto los realizados entre cristianos como entre judíos y cristianos, presentan una característica común: nunca aparece como profesión la de prestamista, lo que permite afirmar que tanto unos como otros ejercieron la actividad prestataria como una segunda ocupación complementaria a su profesión principal ${ }^{23}$.

De las cantidades prestadas tanto por judíos como por cristianos en Galicia, cabe destacar la escasa cuantía de las operaciones así como la utilización de diferentes tipos de monedas, lo que hace más difícil su homologación. En general, predominan los préstamos de pequeñas cantidades -entre 160 y 930 mrs. en los préstamos entre cristianos y entre 20 y 800 mrs. en los judíos- que inducen a pensar en créditos agrícolas o bien en créditos a pequeños artesanos o mercaderes. En la mayoría de los casos el prestamista exigía la devolución de la cantidad prestada en dinero pero, en ocasiones, permitió devolverla tanto en dinero como en un bien e incluso, solamente con un bien.

Un ejemplo del primer tipo se registró en Ourense cuando Gonzalo Anes, mercader, prestó 1200 mrs. a Fernando García, vecino de Zamora, quien los podría devolver en dinero o en una mercancía, sin especificar el tipo «dños. feitos ou en mercador[ias]» ${ }^{24}$. Sin embargo, el bien más habitual fue el vino, uno de los pilares básicos de la economía bajomedieval gallega. Este es el caso de Inés Afonso quién recibió en Ourense de Abrahán de León 175 mrs., que podría entregar bien en dinero «ou de lle dar seus dños», o bien en vino «delos encher en boon viño», según el

${ }^{20}$ M. ${ }^{a}$ G. DE Antonio Rubio, Los judios en Galicia (1044-1492) (A Coruña 2006) págs. 199-200. Más información sobre la vida de estos personajes en M. ${ }^{a}$ G. DE ANTONIO Rubio, Judíos e Inquisición en Ribadavia (Ribadavia 2009) págs. 69-82.

${ }^{21}$ De Antonio Rubio, Los judios en Galicia, págs. 198-199.

${ }^{22}$ López CArreira, «Contribución ó estudo da Xudería ourensá Baixomedieval», págs. 201-217: 214, doc. 30 .

${ }^{23}$ G. TodeschinI, «The Origin of a Medieval Anti-Jewish Stereotype: The Jews as Receivers of Stolen Goods (Twelfth to thirteenth Centuries)» en The Jewish-Christian Encounter in Medieval Preaching, eds. J. AdAMs y J. HANSKA (London 2015) págs. 240252; D. Romano, «Prestadores judíos en los estados hispánicos medievales», Revista Estudios Mirandeses VIII (1988) págs. 117-126: 123.

${ }^{24}$ López CARreira, Libro de notas, pág. 176, doc. 336. 
precio que éste tuviera en la ciudad «nen a mayor valia ne a menor» ${ }^{25}, \mathrm{o}$ el de Afonso Neto, quien prometió pagar los 930 mrs. que debía «en viño branco merchante a esta sazon primeira que ven et nos bos dando o dito biño merchante que vos de et page os ditos maravedis ${ }^{26}$.

En otras ocasiones se permitió entregar solamente el bien, el vino, tal y como muestra, entre otros, un documento datado el 8 de mayo de 1433, en Pontevedra. En esta fecha, el zapatero Juan Boo reconoció que debía $300 \mathrm{mrs}$. que devolvería «en viño ullãao, mosto aa dorna, da viña que eu lavro no couto de Lerez» ${ }^{27}$.

En ninguno de los casos en los que el prestatario tiene que devolver la cantidad de vino equivalente a la cantidad prestada se acuerda por adelantado la cantidad a entregar. Como mucho, en ocasiones, se precisa que el volumen a entregar dependerá del precio que el vino tenga en ese momento en el mercado. Tal es el caso del documento anterior, que continúa indicando que el vino ha de ser «boo et merchante tanto que en el sejades pago, o qual deve seer contado entre nos rasonavelmente a como valuer enton aa dorna ${ }^{28}$. Esto será, precisamente lo que diferenciará este tipo de préstamo del que se analizará en el apartado siguiente, en el que el prestatario se obliga a devolver, en pago del préstamo, una cantidad concreta y pactada de vino o el valor de esa cantidad de vino en el mercado al momento del pago.

En cuanto a las fechas establecidas para los vencimientos coinciden, tanto en los contratos judíos como en los cristianos, con las grandes fiestas religiosas como Navidad, Pascua, Santa María de agosto, San Martín de noviembre o con las de la vendimia.

\subsection{Devolver la cantidad prestada con un bien o su valor en el mercado.}

Esta fórmula consistió en exigir la devolución de la cantidad prestada con un bien o el valor de ese bien en el mercado, pero nunca con el dinero entregado. Será precisamente el hecho de que el prestamista no admita

\footnotetext{
${ }^{25}$ López CARReira, Libro de notas, págs. 75-76, doc. 128.

${ }^{26}$ Rodríguez González y Armas Castro, Minutario notarial, págs. 37-38, doc. 22.

${ }^{27}$ Rodríguez González y Armas Castro, Minutario notarial, pág. 39, doc. 24.

${ }^{28}$ Rodríguez González y Armas Castro, Minutario notarial, pág. 39, doc. 24.
} 
la restitución del dinero prestado lo que marcará la diferencia entre un préstamo tipo y los documentos que se van a analizar en este apartado. La definición de préstamo dada por la Real Academia Española en cualquiera de sus dos acepciones -«cantidad de dinero que se solicita, generalmente a una institución, con la obligación de devolverlo con un interés», o «contrato mediante el cual un particular se obliga a devolver un dinero que le ha sido prestado»- no es muy diferente de la definición dada en el Código Civil:

por el contrato de préstamo, una de las partes entrega a la otra, o alguna cosa no fungible para que use de ella por cierto tiempo y se la devuelva, en cuyo caso se llama comodato, o dinero u otra cosa fungible, con condición de volver otro tanto de la misma especie y calidad, en cuyo caso conserva simplemente el nombre de préstamo.

Es decir, el prestatario se compromete a devolver la misma cantidad prestada, en el caso de un préstamo sin intereses o la cantidad prestada más intereses. Sin embargo, en los documentos que se analizarán a continuación, tal y como ya se ha mencionado, el prestamista sólo permite la devolución con un bien o con su valor en el mercado pero nunca la cantidad prestada inicialmente.

Sirva como ejemplo la anotación inscrita en el Libro de notas de Alvaro Afonso el 5 de julio de 1434, por la que Gomes Ares, se comprometió a entregar a David dos moyos $^{29}$ de vino por los cuarenta mrs. que éste le había prestado:

Anno sobre dito, a $\mathrm{V}^{\mathrm{o}}$ dias do dito mes, Gomes Ares morador en Tibyaas reçebeu enprestados de Davyd prateyro vesiño dOurense, qoreenta mrs. branca en tres dños. de que se deu por pago. Por los quaes ditos XL mrs. se obrigou de lle dar dous moyos de viño a esta vendimia primeira que ven, do viño das suas viñas que labra en Tibiaas, a como valuer regachaan, nen a mayor valía nen a menor et o carreto que o pagen de por meo etç. Pena II etç. etç. Obrigaçon forte e firme etç. ${ }^{30}$

\footnotetext{
${ }^{29}$ Medida de capacidad equivalente a 128 litros; vid. nota 3.

${ }^{30}$ López CARreira, Libro de notas, pág. 166, doc. 311.
} 
2.2.1. Cálculo del precio mínimo de la unidad de medida de un bien (moyo de vino)

El hecho de que la referencia al vino ocultaba un préstamo con interés encubierto se deduce de las profundas diferencias de valor dadas a los moyos de vino en cada contrato, lo que pone de relieve que éste va a ser el elemento que defina el interés aplicado en cada caso. Las cantidades prestadas a cambio de ciertos moyos de vino en la ciudad de Ourense, según registró el notario Álvaro Afonso, fueron las siguientes ${ }^{31}$ :

\begin{tabular}{|l|c|c|}
\hline \multicolumn{3}{|c|}{ Prestamistas judíos } \\
\hline Año 1434 & $\begin{array}{c}\text { Mrs. } \\
\text { prestados }\end{array}$ & $\begin{array}{c}\text { Moyos } \\
\text { a recibir }\end{array}$ \\
\hline 30 de junio & 60 & 2 \\
\hline 5 de julio & 40 & 2 \\
\hline 15 de julio & 56 & 1 \\
\hline 16 de julio & 240 & 5 \\
\hline 14 de septiembre & 20 & 2 \\
\hline
\end{tabular}

\begin{tabular}{|l|c|c|}
\hline \multicolumn{3}{|c|}{ Prestamistas cristianos } \\
\hline Año 1434 & $\begin{array}{c}\text { Mrs. } \\
\text { prestados }\end{array}$ & $\begin{array}{c}\text { Moyos } \\
\text { a recibir }\end{array}$ \\
\hline 16 de marzo & 120 & 3 \\
\hline 16 de marzo & 140 & 4 \\
\hline 31 de julio & 90 & 3 \\
\hline 21 de agosto & 80 & 2 \\
\hline 21 de septiembre & 100 & 2 \\
\hline
\end{tabular}

A la vista de estos datos, cuando el prestamista era judío, el valor del vino varió entre los 56 mrs. por un único moyo, en el caso más caro, y los $10 \mathrm{mrs}$. el moyo $-20 \mathrm{mrs}$. prestados a cambio de dos moyos - en el más barato. Entre los cristianos, el valor del vino varió entre los $30 \mathrm{mrs}$. -90 mrs. a cambio de 3 moyos - en el caso más barato, y los $50 \mathrm{mrs}$. -100 mrs. a cambio de 2 moyos de vino- en el caso más caro. Para calcular el interés realmente aplicado es necesario, primeramente, conocer el valor de un moyo de vino. Su cálculo exacto, teniendo en cuenta las limitaciones impuestas por la documentación, entra dentro del terreno de la especulación. No obstante, sí se puede lograr una aproximación en función de la naturaleza mercantil, ya mencionada, del préstamo. Para ello, se tomará como punto de partida la anotación realizada en Ourense, el 15 de julio de 1434, entre Fernando Ramos y Salomón:

A XV dias do dito mes de jullyo Fernando Ramos vesiño dOurense reçebeu enprestados de Salamon prateyro vesiño dOurense çinqoeenta e

${ }^{31}$ Para los prestamistas judíos seguimos a LóPEz CARREIRA, Libro de notas, págs. 163, $166,171-172,173-174$ y 210 , docs. $303,311,325,330$ y 413 ; en tanto que los datos sobre los prestamistas cristianos se extraen de las págs. 84, 84-85, 174, 183 y 218, docs. 149, $150,332,353$ y 428. 
seys mrs. branca en tres dños. de que de deu por pago con XL .- que lle devia dante, por los quaes ditos çinqoeenta et seys mrs. se obrigou de lle dar hun moyo de viño de lagar a esta dorna primeira que ven, nen a mayor valía nen a menor, rega chaan, forro e quite de alcavala etç. Penna a mayor valía de agosto etç. Obrigaçon forte e firme etç. ${ }^{32}$

Las razones de la elección de este documento son dos. La primera, que el uso de la expresión «reçebeu enprestados» define, sin lugar a dudas, un préstamo de tipo mercantil. La segunda, que el documento recoge la entrega de un único moyo de vino a cambio de los 56 mrs. que Salomón le prestó a Fernando Ramos. Dado que es impensable que el prestamista no obtuviera ningún beneficio con esta transacción, el valor real del moyo debería ser superior a los 56 mrs. prestados. Sin embargo, como es imposible conocer cuánto más valdría el vino, se tomará esta cantidad, 56 mrs., como el valor de un moyo, aun sabiendo que sería superior a esta cantidad. Esta afirmación se ve reforzada tanto por dos documentos de compraventa, recogidos en el mismo libro de notas y realizados el 4 de marzo ${ }^{33}$ y 9 de septiembre ${ }^{34}$ del mismo año, en los que se vendió un moyo de vino por 60 mrs., como por el caso de aquel al que prestaron 240 mrs. por 5 moyos de vino que se mencionará más adelante.

\subsubsection{Aproximación al porcentaje de interés realmente aplicado}

Si el prestamista, Salomón, hubiese aplicado el 33\%, «tres por cuatro», sobre los 56 mrs. prestados, el valor del vino habría ascendido hasta los 74,48 mrs. No obstante, su valor real debía ser superior a esta cantidad puesto que el prestamista no exigió la restitución de 74,48 mrs. sino la un moyo. Con este sistema de devolución, el auténtico beneficio quedó oculto bajo el valor real del vino, lo que permite suponer que el interés aplicado a los 56 mrs. fue superior al habitual. Si el prestamista hubiese aplicado un «dos por tres», esto es, el $50 \%$, el valor del vino habría sido equivalente a 84 mrs., valor que habría ascendido hasta los 112 mrs. si se hubiese aplicado un «uno por dos», o sea, el $100 \%{ }^{35}$.

\footnotetext{
${ }^{32}$ LÓPEZ CARReIra, Libro de notas, págs. 171-172, doc. 325.

${ }^{33}$ López CARreira, Libro de notas, pág. 76, doc. 129.

${ }^{34}$ López CARreira, Libro de notas, págs. 208-209, doc. 409.

$3574,48=56+(56 * 0,33) ; 84=56+(56 * 0,50) ; 112=56+(56 * 1)$.
} 
En el caso más barato, aquel al que se prestaron 20 mrs. por 2 moyos, considerando el valor mínimo del moyo equivalente a $56 \mathrm{mrs}$, tendría que devolver en vino el equivalente a $112 \mathrm{mrs}$. ( 2 moyos por $56 \mathrm{mrs}$. el moyo), lo que supondría unos intereses de 92 mrs.:

Cantidad a devolver $=$ cantidad prestada + intereses

112 mrs. $=20+$ intereses

Intereses $=112-20=92 \mathrm{mrs}$.

Para calcular el porcentaje que supusieron los 92 mrs. sobre los 20 mrs. prestados, se aplicará la fórmula de cálculo del interés simple anual sobre los intereses:

$$
\begin{aligned}
& \text { Intereses }=(\text { capital } * \text { rédito } * \text { tiempo }) / 100 \\
& 92=(20 * \mathrm{r} * 1) / 100 \\
& 92=20 \mathrm{r} / 100 ; \mathrm{r}=92 * 100 / 20 \\
& \mathrm{R}=9200 / 20=460 \% \text { anual }
\end{aligned}
$$

Si el prestamista hubiese aplicado el 33\% sobre el precio mínimo del moyo, 56 mrs., el prestatario habría tenido que pagar el equivalente a 148 mrs. ( 2 moyos por $74 \mathrm{mrs}$. el moyo), lo que equivaldría a $128 \mathrm{mrs}$. de intereses y un porcentaje anual del $640 \%$. Porcentaje que ascendería hasta $740 \%$

\begin{tabular}{|c|c|}
\hline \multicolumn{2}{|c|}{20 mrs. por 2 moyos } \\
\hline $\begin{array}{c}\text { Precio mínimo } \\
\text { (56 mrs. por moyo) }\end{array}$ & $\begin{array}{c}2 \text { moyos } \mathrm{x} 56 \mathrm{mrs} .=112 \mathrm{mrs} . \\
\text { Intereses }=112-20=92 \mathrm{mrs} . \\
\text { Cálculo del porcentaje. } \\
\text { Interés }=(\text { cantidad } * \text { rédito } * \text { tiempo }) / 100 \\
92=20 \mathrm{r} / 100 ; \mathrm{r}=92 * 100 / 20 \\
\mathrm{r}=9200 / 20=\mathbf{4 6 0} \% \text { anual }\end{array}$ \\
\hline $\begin{array}{c}33 \% \text { interés } \\
\text { (74 mrs. por moyo) }\end{array}$ & $\begin{array}{c}2 \text { moyos } \times 74 \text { mrs. }=148 \mathrm{mrs} . \\
\text { Intereses }=148-20=128 \mathrm{mrs} . \\
\text { Cálculo del porcentaje. } \\
\mathrm{r}=128 * 100 / 20=\mathbf{6 4 0 \%} \text { anual }\end{array}$ \\
\hline $\begin{array}{c}50 \% \text { interés } \\
\text { (84 mrs. por moyo) }\end{array}$ & $\begin{array}{l}2 \text { moyos } \times 84 \text { mrs. }=168 \text { mrs. } \\
\text { Intereses }=168-20=148 \mathrm{mrs} \text {. } \\
\text { Cálculo del porcentaje. } \\
\mathrm{r}=148 * 100 / 20=740 \% \text { anual }\end{array}$ \\
\hline
\end{tabular}
si el moyo de vino equivaliese a $84 \mathrm{mrs}$. al haberle aplicado un $50 \%$ de interés. A modo de resumen, los porcentajes que habrían supuesto los intereses aplicados por $20 \mathrm{mrs}$. a cambio de dos moyos de vino habrían sido: 
En los cálculos anteriores se ha considerado un año como la variable tiempo debido a que es la fórmula general del interés simple y a que la documentación no ofrece la fecha real del préstamo sino la fecha en que el prestamista se obligó a pagar, ante el notario, la cantidad prestada. A pesar de esta circunstancia, en ninguno de los contratos analizados la fecha de vencimiento es superior a este período. Para intentar una mayor aproximación en el documento que se está analizando -el realizado el 15 de julio de $1434^{36}$ entre Fernando Ramos y Salomón- se considerará que el contrato de préstamo y la anotación ante el notario se hicieron el mismo día. Como el prestatario se comprometió a devolver el vino en la vendimia «a esta dorna primeira que ven», y dado que ésta suele ser a finales de septiembre, el préstamo bien pudo ser por un mes o, incluso por 15 días. En estos casos los porcentajes de interés aplicados ascenderían a 12 veces más en un mes y a 24 veces más si se tratase de quince días.

Como se ha mencionado anteriormente, la idea de que el precio del vino debía de ser muy superior a los 56 mrs. se ratifica en el caso de aquel que recibió 240 mrs. a cambio de cinco moyos y que, en consecuencia, tendría que devolver en vino el equivalente a $280 \mathrm{mrs}$. (5 moyos x $56 \mathrm{mrs}$. el moyo), lo que supondría unos intereses de $40 \mathrm{mrs}$.:

Cantidad a devolver $=$ cantidad prestada + intereses

$280=240+$ intereses; Intereses $=280-240=40 \mathrm{mrs}$.

Aplicando la fórmula del interés simple anual:

$$
\begin{aligned}
& \text { Interés }=\text { cantidad } * \text { rédito } * \text { tiempo } / 100 \\
& 40=(240 * \mathrm{r} * 1) / 100 ; 40=240 \mathrm{r} / 100 ; \mathrm{r}=40 * 100 / 240 ; \\
& \mathrm{R}=4000 / 240=16,6 \% \text { anual }
\end{aligned}
$$

Porcentaje claramente inferior al 33\% habitual.

Por el contrario, si sobre los 56 mrs. se hubiese aplicado un 33\%, el valor de moyo sería de $74 \mathrm{mrs}$. y el porcentaje de interés el 54,11\%. En el caso de haber aplicado un 50\% sobre la cantidad inicial prestada, el valor del moyo, ascendería a $84 \mathrm{mrs}$. lo que supondría un $75 \%$ de interés aplicado. Ambos porcentajes superiores al 33\% y que, por lo tanto, debían ser ocultados bajo la entrega de un bien. A modo de resumen, los porcentajes que habrían sido aplicados son los siguientes:

\footnotetext{
${ }^{36}$ LóPEZ CARreira, Libro de notas, págs. 171-172, doc. 325.
} 


\begin{tabular}{|c|c|}
\hline $\begin{array}{c}\text { Precio mínimo } \\
\text { (56 mrs. por moyo) }\end{array}$ & $\begin{array}{l}5 \text { moyos x } 56 \mathrm{mrs} .=280 \mathrm{mrs} \\
280 \mathrm{mrs}=\text { cantidad prestada }+ \text { intereses } \\
\text { Intereses }=280-240=40 \mathrm{mrs} . \\
\text { Cálculo del porcentaje. } \\
\text { Interés }=\text { cantidad } * \text { rédito } * \text { tiempo } 100 \\
40=240 \mathrm{r} / 100 \\
\mathrm{r}=40 * 100 / 240 \\
\mathrm{r}=4000 / 240=\mathbf{1 6 , 6} \% \text { anual }\end{array}$ \\
\hline $\begin{array}{c}33 \% \text { interés } \\
\text { (74 mrs. por moyo) }\end{array}$ & $\begin{array}{c}5 \text { moyos } \times 74 \text { mrs. }=370 \mathrm{mrs} . \\
370 \mathrm{mrs}=\text { cantidad prestada }+ \text { intereses } \\
\text { Intereses }=370-240=130 \mathrm{mrs} . \\
\text { Cálculo del porcentaje. } \\
\mathrm{r}=130 * 100 / 240=\mathbf{5 4 , 1 \%} \text { anual }\end{array}$ \\
\hline $\begin{array}{c}50 \% \text { interés } \\
(84 \text { mrs. per moyo) }\end{array}$ & $\begin{array}{c}5 \text { moyos } \times 84 \text { mrs. }=420 \mathrm{mrs} \text {. } \\
420 \mathrm{mrs}=\text { cantidad prestada }+ \text { intereses } \\
\text { Intereses }=420-240=180 \mathrm{mrs} \text {. } \\
\text { Cálculo del porcentaje. } \\
\mathrm{r}=180 * 100 / 240=\mathbf{7 5} \% \text { anual }\end{array}$ \\
\hline
\end{tabular}

Aplicando los cálculos anteriores a la totalidad de los contratos realizados por los judíos de Ourense en 1434, teniendo en cuenta que el epígrafe Cant. a devolver se refiere al equivalente en mrs. del valor del vino, se obtienen los siguientes porcentajes:

\begin{tabular}{|c|c|c|c|c|c|}
\hline \multicolumn{6}{|c|}{$\begin{array}{c}\text { Préstamos con interés superior al legal } \\
\text { realizados por judíos }\end{array}$} \\
\hline $\begin{array}{l}\text { Año } \\
1434\end{array}$ & $\begin{array}{l}\text { Mrs. } \\
\text { prestados }\end{array}$ & $\begin{array}{l}\text { Moyos } \\
\text { a recibir }\end{array}$ & $\begin{array}{l}\text { Cant. a devolver } \\
\% \text { aplicado } \\
\text { (moyo = } 56 \text { mrs.) }\end{array}$ & $\begin{array}{l}\text { Cant. a devolver } \\
\% \text { aplicado } \\
\text { (moyo }=74 \text { mrs.) }\end{array}$ & $\begin{array}{c}\text { Cant. a devolver } \\
\% \text { aplicado } \\
\text { (moyo }=\mathbf{8 4} \\
\text { mrs.) }\end{array}$ \\
\hline 30 de junio & 60 & 2 & $\begin{array}{l}112 \mathrm{mrs} \text {. } \\
\mathbf{8 6 , 6 \%}\end{array}$ & $\begin{array}{l}148 \mathrm{mrs} . \\
\mathbf{1 4 6 , 6 \%}\end{array}$ & $\begin{array}{l}168 \mathrm{mrs} \text {. } \\
\mathbf{1 8 0 \%}\end{array}$ \\
\hline 5 de julio & 40 & 2 & $\begin{array}{l}112 \mathrm{mrs} \text {. } \\
\mathbf{1 8 0 \%}\end{array}$ & $\begin{array}{l}148 \mathrm{mrs} . \\
\mathbf{2 7 0} \%\end{array}$ & $\begin{array}{l}168 \mathrm{mrs} \text {. } \\
\mathbf{3 2 0 \%}\end{array}$ \\
\hline 15 de julio & 56 & 1 & $\begin{array}{l}56 \mathrm{mrs} . \\
\mathbf{0 \%}\end{array}$ & $\begin{array}{l}74 \mathrm{mrs} \text {. } \\
\mathbf{3 3 , 3} \%\end{array}$ & $\begin{array}{l}84 \mathrm{mrs} \text {. } \\
\mathbf{5 0 \%}\end{array}$ \\
\hline 16 de julio & 240 & 5 & $\begin{array}{l}280 \mathrm{mrs} \text {. } \\
\mathbf{1 6 , 6 \%}\end{array}$ & $\begin{array}{l}370 \mathrm{mrs} \text {. } \\
\mathbf{5 4 , 1 \%}\end{array}$ & $\begin{array}{l}420 \mathrm{mrs} \text {. } \\
\mathbf{7 5 \%}\end{array}$ \\
\hline 14 de septiembre & 20 & 2 & $\begin{array}{l}112 \mathrm{mrs} \text {. } \\
\mathbf{4 6 0 \%}\end{array}$ & $\begin{array}{l}148 \mathrm{mrs} . \\
\mathbf{6 4 0 \%}\end{array}$ & $\begin{array}{l}168 \mathrm{mrs} . \\
\mathbf{7 4 0 \%}\end{array}$ \\
\hline
\end{tabular}


De estos datos puede deducirse que dos moyos de vino o su valor es la cantidad de vino exigida con más frecuencia puesto que se recoge en una obligación realizada el 30 de junio en la que se prestaba esta cantidad a cambio de $60 \mathrm{mrs}$; el 5 de julio por 40 mrs., además de la ya analizada de 20 mrs. el 14 de septiembre. Esta variación en las cantidades prestadas a cambio de la misma cantidad de vino puede deberse a la confianza entre prestador y prestatario o al conocimiento por parte del prestamista de las viñas y el tipo de vino que el prestatario, siempre productor de vino, podía ofrecer, ya que es habitual encontrar en los documentos precisiones sobre de dónde debe proceder el vino, «das suas viñas que labra en esta çidade e arredor dela» ${ }^{37}$, e incluso de viñas concretas, «de suas viñas que labra en «Tibiaas» o en «Barbadaas» ${ }^{38}$. Estas exigencias son menos frecuentes entre los cristianos puesto que solamente se menciona que el vino tiene que ser «das suas viñas que labra arredor desta dita çidade» o de «Çaame»".

En las ocasiones en las que el prestamista fue cristiano el valor del vino varió entre los $50 \mathrm{mrs}$. $-100 \mathrm{mrs}$. prestados por dos moyos-, en el caso más caro, y los $30 \mathrm{mrs}$. el moyo $-90 \mathrm{mrs}$. prestados a cambio de tres moyos- en el más barato. Por lo que aplicando los mismos cálculos que cuando el prestamista era judío, los posibles porcentajes aplicados fueron:

\begin{tabular}{|c|c|c|c|c|c|}
\hline \multicolumn{6}{|c|}{$\begin{array}{l}\text { Préstamos con interés superior al legal } \\
\text { realizados entre cristianos }\end{array}$} \\
\hline $\begin{array}{l}\text { Año } \\
1434\end{array}$ & $\begin{array}{c}\text { Mrs. } \\
\text { Prestados }\end{array}$ & $\begin{array}{l}\text { Moyos } \\
\text { a recibir }\end{array}$ & $\begin{array}{l}\text { Cant. a devolver } \\
\% \text { aplicado } \\
\text { (moyo = } 56 \text { mrs.) }\end{array}$ & $\begin{array}{l}\text { Cant. a devolver } \\
\% \text { aplicado } \\
\text { (moyo = } 74 \text { mrs.) }\end{array}$ & $\begin{array}{c}\text { Cant. a devolver } \\
\% \text { aplicado } \\
\text { (moyo }=\mathbf{8 4} \text { mrs.) }\end{array}$ \\
\hline 16 de marzo & 120 & 3 & $\begin{array}{l}168 \mathrm{mrs} . \\
\mathbf{4 0 \%}\end{array}$ & $\begin{array}{l}222 \mathrm{mrs} \\
\mathbf{8 5 \%}\end{array}$ & $\begin{array}{l}252 \mathrm{mrs} . \\
\mathbf{1 1 0 \%}\end{array}$ \\
\hline 16 de marzo & 140 & 4 & $\begin{array}{l}224 \mathrm{mrs} \text {. } \\
\mathbf{6 0 \%}\end{array}$ & $\begin{array}{l}296 \mathrm{mrs} \text {. } \\
\mathbf{1 1 1 , 4 \%}\end{array}$ & $\begin{array}{l}336 \mathrm{mrs} . \\
\mathbf{1 4 0 \%}\end{array}$ \\
\hline 31 de julio & 90 & 3 & $\begin{array}{l}168 \mathrm{mrs} . \\
\mathbf{8 6 , 6 \%}\end{array}$ & $\begin{array}{l}222 \mathrm{mrs} . \\
146,6 \%\end{array}$ & $\begin{array}{l}252 \mathrm{mrs} . \\
\mathbf{1 8 0 \%}\end{array}$ \\
\hline 21 de agosto & 80 & 2 & $\begin{array}{l}112 \mathrm{mrs} . \\
\mathbf{4 0 \%}\end{array}$ & $\begin{array}{l}148 \mathrm{mrs} \text {. } \\
\mathbf{8 5 \%}\end{array}$ & $\begin{array}{l}168 \mathrm{mrs} . \\
\mathbf{1 1 0 \%}\end{array}$ \\
\hline 21 de septiembre & 100 & 2 & $\begin{array}{l}112 \mathrm{mrs} . \\
\mathbf{1 2 \%}\end{array}$ & $\begin{array}{l}148 \mathrm{mrs} \text {. } \\
\mathbf{4 8 \%}\end{array}$ & $\begin{array}{l}168 \mathrm{mrs} . \\
\mathbf{6 8 \%}\end{array}$ \\
\hline
\end{tabular}

${ }^{37}$ López CARreira, Libro de notas, págs. 163 y 183, docs. 303 y 353.

${ }^{38}$ López CARReIra, Libro de notas, págs. 166 y 173-174, docs. 311 y 330.

${ }^{39}$ LÓPEZ CARREIRA, Libro de notas, págs. 84-85 y 174, docs. 150 y 332. 
Del análisis conjunto de los datos expuestos en los gráficos anteriores, la primera conclusión que se puede extraer es obvia: tanto unos como otros, judíos como cristianos, utilizaron la fórmula de esconder los verdaderos intereses cobrados permitiendo la devolución de la cantidad prestada con un bien o su valor en el mercado. La segunda, que es el valor del moyo el que define el interés aplicado en cada caso. La tercera, el escaso número de contratos con interés encubierto realizados por unos y por otros. En el caso que se está analizando, Ourense en 1434, hubo escasas diferencias en cuanto al número de obligaciones realizadas por judíos o por cristianos. Sin embargo, al tratarse de un único año, estas cantidades no son lo suficientemente significativas como para extrapolar a otras comunidades gallegas o de fuera de Galicia la afirmación de que judíos y cristianos, en casi la misma proporción, ocultaron intereses permitiendo la devolución de la cantidad prestada con un bien.

\section{Conclusiones}

Las limitaciones legales existentes para el ejercicio del préstamo con interés, obligaron a los prestamistas, cristianos y judíos, a buscar fórmulas aparentemente legales para ocultar los verdaderos beneficios. De la documentación crediticia gallega del siglo xv, se pueden extraer dos modelos que, independientemente del lugar donde se realice el contrato y de las veces que éste se repita, permiten reconocer un préstamo con interés encubierto. En unos casos, incluyeron los intereses en la cantidad prestada, por lo que el prestatario se comprometía a devolver la misma cantidad que había recibido, adquiriendo el préstamo, de esta manera, un carácter gratuito. Sin embargo, la propia naturaleza mercantil del préstamo -conseguir beneficios por adelantar y poner en riesgo ciertos bienes-así como el hecho de que la cantidad pactada no fuese entregada delante del notario sino en un momento anterior, obligándole, de esta manera, a dar fe solamente de lo que las partes afirmaban, permiten concluir que este tipo de documentos recogen un préstamo con interés encubierto. Tanto cristianos como judíos utilizaron esta fórmula con una estructura similar excepto por el uso de la expresión «por me facer gracia» -en alusión al préstamo gratuito- y el término «renuncio» -en alusión a quien debe presentar las pruebas en caso de reclamación por incumplimiento- que suelen aparecer cuando los prestamistas eran cristianos. En otros casos, exigieron la devolución de la can- 
tidad prestada con un bien o el valor de ese bien en el mercado, pero nunca el dinero entregado. En la documentación gallega, concretamente en la de Ourense, el interés aplicado se deduce de las profundas diferencias de valor dadas a los moyos de vino, bien utilizado en todos los contratos analizados. Aun tratándose de cálculos altamente especulativos -se desconoce el precio exacto del moyo de vino que se ha asumido que sería, como mínimo, de 56 mrs.- al aplicar la fórmula del cálculo del interés simple se obtiene que los interés anuales aplicados llegaron a un máximo de $740 \%$, en el caso de un prestamista judío y de $180 \%$ cuando se trató de un préstamo entre cristianos, ambos porcentajes, evidentemente, muy por encima del 33\% habitual en la Edad Media y que llegaron a ser extremadamente altos cuando el cálculo se circunscribe a un mes o una quincena. En consecuencia, ante lo anteriormente expuesto, se puede concluir que tanto cristianos como judíos, recurrieron a diferentes técnicas de encubrimiento de los intereses realmente cobrados para evitar las restricciones legales existentes para la obtención de beneficios en un préstamo.

Recibido: 20/12/2015

Aceptado: 07/07/2016 